\title{
₹USGS
}

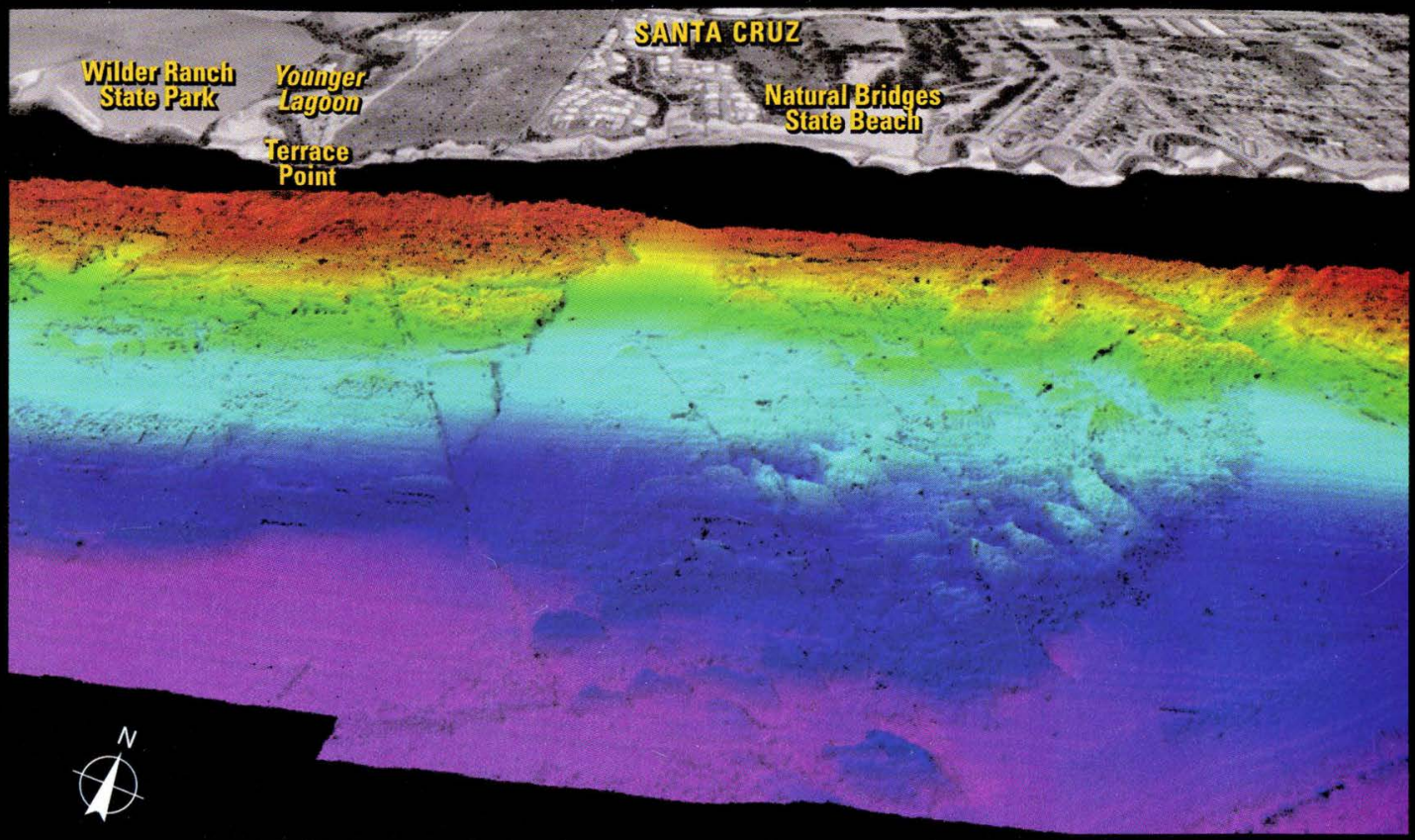

Seafloor off Natural Bridges State Beach, Santa Cruz, California 


\section{The seafloor off Natural Bridges State Beach, Santa Cruz,}

California, is extremely varied, with sandy flats, boulder fields, faults, and complex bedrock ridges. These ridges support rich marine ecosystems; some of them form the "reefs" that produce world-class surf breaks. Colors indicate seafloor depth, from red-orange (about 2 meters or 7 feet) to magenta (25 meters or 82 feet).

Mapped in 2005 and 2006 by the U.S. Geological Survey, with support from the California Department of Boating and Waterways, the Santa Cruz County Redevelopment Agency, and the Santa Cruz County Department of Public Works. Vertical exaggeration: 5x. Approximate distance across bottom of image: 2.2 kilometers (1.4 miles). Learn more at http://pubs.usgs.gov/sim/3007/. 